Original Article

Artigo Original

Amanda Freitas Valentim ${ }^{1}$

Renata Maria Moreira Moraes Furlan ${ }^{2}$ Tatiana Vargas de Castro Perilo ${ }^{3}$

Monalise Costa Batista Berbert ${ }^{4}$

Andréa Rodrigues Motta ${ }^{5}$

Estevam Barbosa de Las Casas ${ }^{6}$

Keywords

Muscle strength

Tongue

Lip

Tooth

Bioengineering

Descritores

Força muscular

Língua

Lábio

Dente

Bioengenharia

Correspondence address:

Amanda Freitas Valentim

Rua David Campista, 207/501,

Floresta, Belo Horizonte (MG), Brasil,

CEP: 30150-090.

E-mail: amandafvalentim@gmail.com

Received: $12 / 10 / 2013$

Accepted: 05/15/2014

\section{Evaluation of the force applied by the tongue and lip on the maxillary central incisor tooth}

\author{
Avaliação da força aplicada por língua e lábio no dente \\ incisivo central superior
}

\begin{abstract}
Purpose: To describe the development and testing of a system that measures forces exerted by the tongue and upper lip on a tooth during rest and during swallowing. Methods: Twenty-eight subjects, aged 19-31 years (mean: 23.2 years) were submitted to measurement of forces exerted by the upper lip and tongue on the maxillary right central incisor tooth. Flexiforce resistive sensors were fixed on the labial and lingual surfaces of the tooth. They were connected to an amplifier circuit and a data acquisition board for processing and transmitting information to a computer. Results: At rest, the tongue force on the tooth was $0.00 \pm 0.00 \mathrm{~N}$ and the lip force on tooth was $0.02 \pm 0.02 \mathrm{~N}$. The difference between them was significant. During swallowing, the values were $0.31 \pm 0.38 \mathrm{~N}$ and $0.15 \pm 0.14 \mathrm{~N}$, for the tongue and lip, respectively. This difference was not significant. Conclusion: At rest, the lip exerts a larger force than the tongue on the maxillary right central incisor tooth. During swallowing, there was no difference between lip and tongue force on the tooth.
\end{abstract}

\section{RESUMO}

Objetivo: Descrever o desenvolvimento e os testes de um método para medir as forças exercidas por lábio e língua sobre um dente durante posição habitual e deglutição. Métodos: Vinte e oito sujeitos (10 homens e 18 mulheres), com idades variando entre 19 e 31 anos (média de 23,2 anos) foram submetidos à medição das forças exercidas pelo lábio superior e pela língua no dente incisivo central superior direito. Para tal, sensores resistivos Flexiforce foram fixados nas superfícies vestibular e palatina desse dente. Os sensores estavam conectados a um circuito amplificador e a uma placa de aquisição de dados para processamento e transmissão das informações a um computador. Resultados: Durante a posição habitual, a força da língua no dente foi de $0,00 \pm 0,00 \mathrm{~N}$ e a do lábio, de $0,02 \pm 0,02 \mathrm{~N}$, sendo essa diferença significante. Durante a deglutição, esses valores foram de $0,31 \pm 0,38 \mathrm{~N}$ e $0,15 \pm 0,14 \mathrm{~N}$, para língua e no lábio, respectivamente, sem diferença significante. Conclusão: Em posição habitual, o lábio exerce uma força maior do que a língua sobre o dente incisivo enquanto, durante a deglutição, não se verificou diferença entre força de língua e lábio sobre esse dente.

Study carried out at the Postgraduate Department in Mechanical Engineering, Universidade Federal de Minas Gerais - UFMG - Belo Horizonte (MG), Brazil.

(1) Prefeitura Municipal de Nova Lima - Nova Lima (MG), Brazil.

(2) Universidade Federal de Minas Gerais - UFMG - Belo Horizonte (MG), Brazil.

(3) Instituto Metodista Izabela Hendrix - Belo Horizonte (MG), Brazil.

(4) Universidade Federal do Rio Grande do Sul - UFRGS - Porto Alegre (RS), Brazil.

(5) Department of Speech Language Pathology and Audiology, Universidade Federal de Minas Gerais - UFMG Belo Horizonte (MG), Brazil.

(6) Department of structural engineering, Universidade Federal de Minas Gerais - UFMG-Belo Horizonte (MG), Brazil. Financial support: National Council for Scientific and Technological Development (CNPq).

Conflict of interests: nothing to declare. 


\section{INTRODUCTION}

The teeth are submitted to forces that balance each other. Tooth movement occurs when a force is greater or lasts longer than its countering force. The duration of the force is more important than its magnitude. Therefore, light forces exerted by the lips, cheeks, and tongue at rest are more important than intermittent forces, such as forces exerted during speech, mastication, and swallowing ${ }^{(1)}$. Speech-language pathologists and dentists routinely evaluate the habitual position of the tongue qualitatively. The force of this structure is also assessed in a perceptive way. The speech-language pathologist asks a patient to contract the tongue and make a contraction against a resistance, and based on experience, the pathologist classifies the force as normal or impaired ${ }^{(2)}$. These evaluations are subjective and make it more difficult to accurately diagnose a patient.

Different devices based on force and pressure transducers have been developed to measure lip strength ${ }^{(3,4)}$, tongue strength $^{(5,6)}$, or both ${ }^{(7-9)}$. Some devices that measure lip strength ${ }^{(10)}$ or tongue strength ${ }^{(11)}$ on the teeth are based on water infusion systems, and some devices use palatal plates with pressure sensors or a sensor sheet on the palate to measure tongue force on the palate ${ }^{(12-14)}$.

To accomplish a more accurate diagnosis of lip and tongue strength against a tooth during their habitual positions and during swallowing, the present pilot study describes a method of measuring the tongue and lip force against the maxillary central incisor and presents the results.

\section{METHODS}

This pilot study was approved by the Ethics Committee of Universidade Federal de Minas Gerais by the number 0253/11. The study sample comprised 28 individuals (10 male and 18 female) who ranged from 19 to 31 years of age (average age: $23.2 \pm 2.9$ years). The inclusion criteria were individuals who were at least 18 years of age and had signed an Informed Consent. The exclusion criteria were previous glossectomies, paralysis or paresis of lips or tongue, cognitive impairment, use of braces or dental restraint in the maxillary arch, orthodontic treatment that was completed less than 2 years before the study, current speech-language therapy, or nasal obstruction at the time of the evaluation.

An occlusal assessment was first performed by a speechlanguage pathologist post graduated in orofacial myology. The bite of the anterior teeth was visualized with the aid of a tongue blade. The bite was classified as normal, overbite, overjet, open bite, crossbite, edge-to-edge bite, or with crowding or spacing. Occlusion was analyzed according to Angle's classification.

The system used to measure forces contains two Flexiforce resistive sensors (Tekscan, Boston, MA, USA) with a 9.53-mm diameter, $0.2-\mathrm{mm}$ thickness, and measurement range from 0.0 to $4.4 \mathrm{~N}$ (Figure 1). These sensors are connected to an amplifier circuit, an acquisition board system NI USB 6008 (National Instruments, Austin, TX, USA), and a computer.
The sample rate was $70 \mathrm{~Hz}$ and data were displayed in a program developed with LabVIEW (National Instruments, Austin, TX, USA), that shows a force-time history graph for each of the two channels.

The sensors were cleaned with $70 \%$ alcohol, coated with PVC film, and fixed onto the maxillary right central incisor with an adhesive resin Corega (GlaxoSmithKline Brasil Ltda., Rio de Janeiro, RJ, Brazil). One sensor was placed on the labial surface and the other, on the palatal surface (Figure 2). The box containing the sensors' connectors was attached to the subject's neck to hold its weight (Figure 3).

After fixing the sensors, the evaluator waited 30 seconds for the subject to become accommodated to the sensors. The subjects were then instructed to swallow saliva (i.e., first test), which was recorded. This swallow was used to guide the evaluator concerning the swallowing force profile of each participant, so the swallowing could be identified for the next measurement.

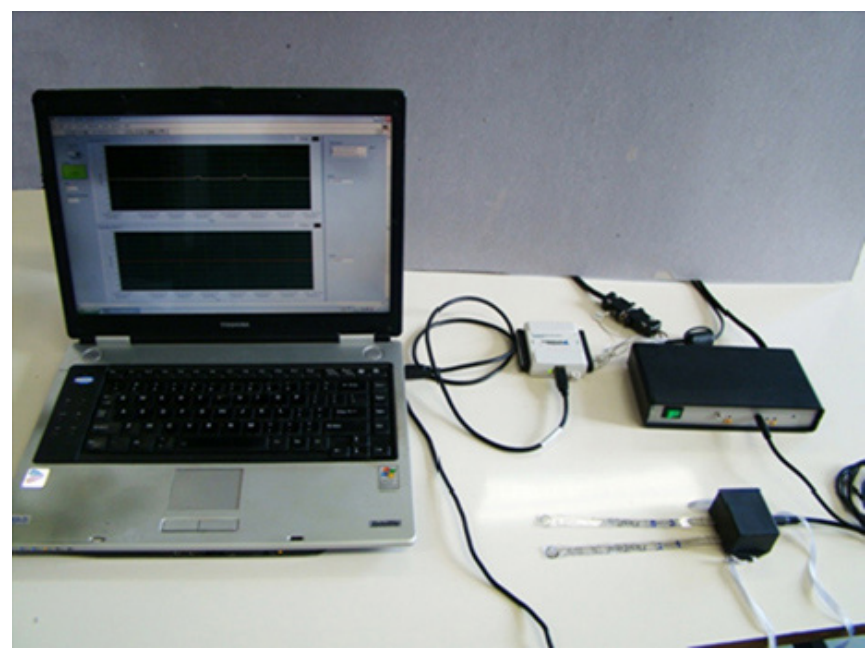

Figure 1. The measurement system

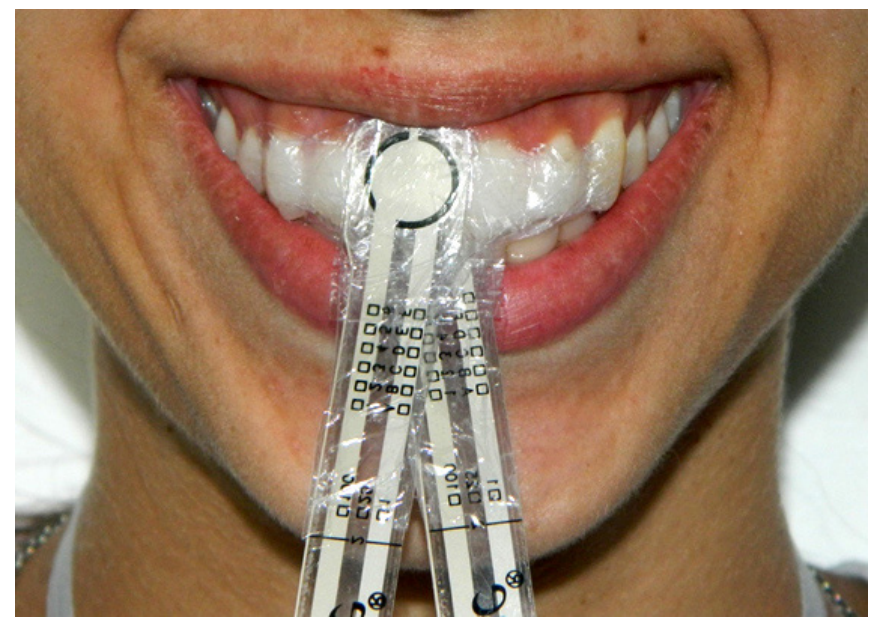

Figure 2. The sensors positioned on the incisor 


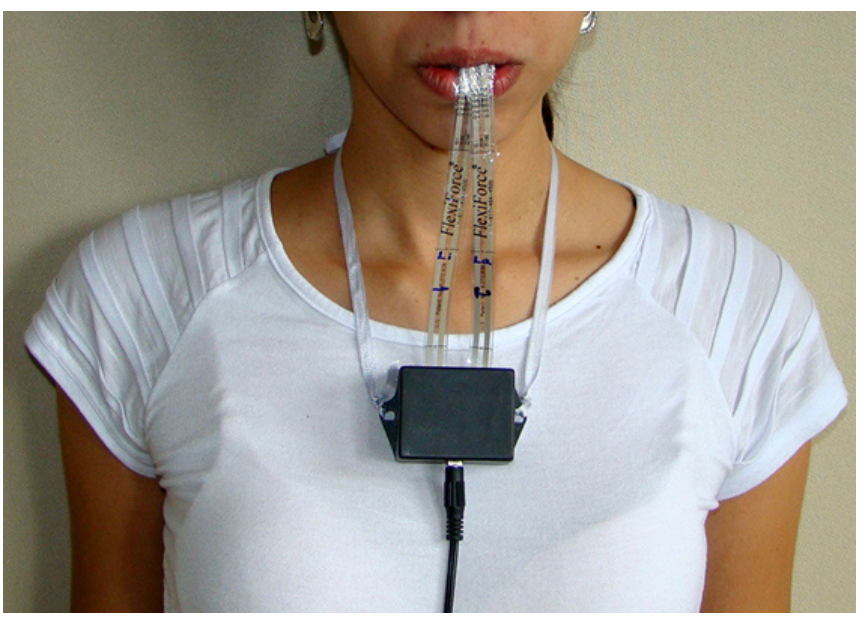

Figure 3. The box positioned with the connectors of the sensors

A new measurement was then performed. The evaluator requested a participant to maintain the tongue and lips in their habitual positions (keep these structures where they use to be when the subject is doing nothing with the mouth) and swallow whenever necessary (i.e., second test). The participants meanwhile performed an auditory distraction activity in which they listened to a story and had to count on their fingers how many times a specific word appeared. This activity was designed to prevent monitoring and lasted about one minute and 30 seconds.

Participants with no visible spontaneous swallowing during the second test were asked to perform two more saliva swallows (i.e., third test). Thus, all participants had at least three swallows for analysis.

To evaluate the habitual position, three 10 -second rest periods were selected in the second test at the beginning, the middle, and the end of the test. The average and maximum force of the tongue and lip on the tooth were analyzed. The average force for each subject was the average of the values obtained on the three periods and maximum force was the average of maximum forces obtained on the three sections.
The maximum tongue and lip forces on the tooth and the duration of the tongue touch on the tooth during instructed swallowing (i.e., first and third tests) and spontaneous swallowing (i.e., second test) were evaluated. If the participant had no apparent peak force during instructed swallowing, then the maximum value from the first test was considered the maximum swallowing force. Thus, these participants had only one value for tongue force and one value for lip force, regardless of how many swallows they performed. They did not have force versus time responses. To check the balance between the lip and tongue forces on the tooth, the average lip force of each participant was subtracted from the average tongue force at the habitual position and during swallowing.

The Wilcoxon and the Mann-Whitney tests was the nonparametric tests used for statistical analysis. A p-value $<0.05$ was considered significant.

\section{RESULTS}

After calibrating the measurement system, the tongue and lip forces on the tooth and swallowing touch duration were measured.

\section{Force measurements}

Table 1 shows the average lip and tongue forces of all participants during the habitual position and during swallowing.

Table 2 presents each participant's results for the tongue and lip forces during the habitual position and during swallowing.

The average force for all subjects during instructed swallowing was $0.34 \mathrm{~N}$ for the tongue and $0.15 \mathrm{~N}$ for the lip. The values for spontaneous swallowing were $0.52 \mathrm{~N}$ for the tongue and $0.17 \mathrm{~N}$ for the lip.

Figure 4 is a graph illustrating the measurement of the tongue force in the second test (i.e., the habitual position with spontaneous swallowing). Figure 5 shows the peak force of the tongue during swallowing.

Table 1. Comparison between lip and tongue forces on the teeth, in Newtons, during habitual position and first instructed swallowing

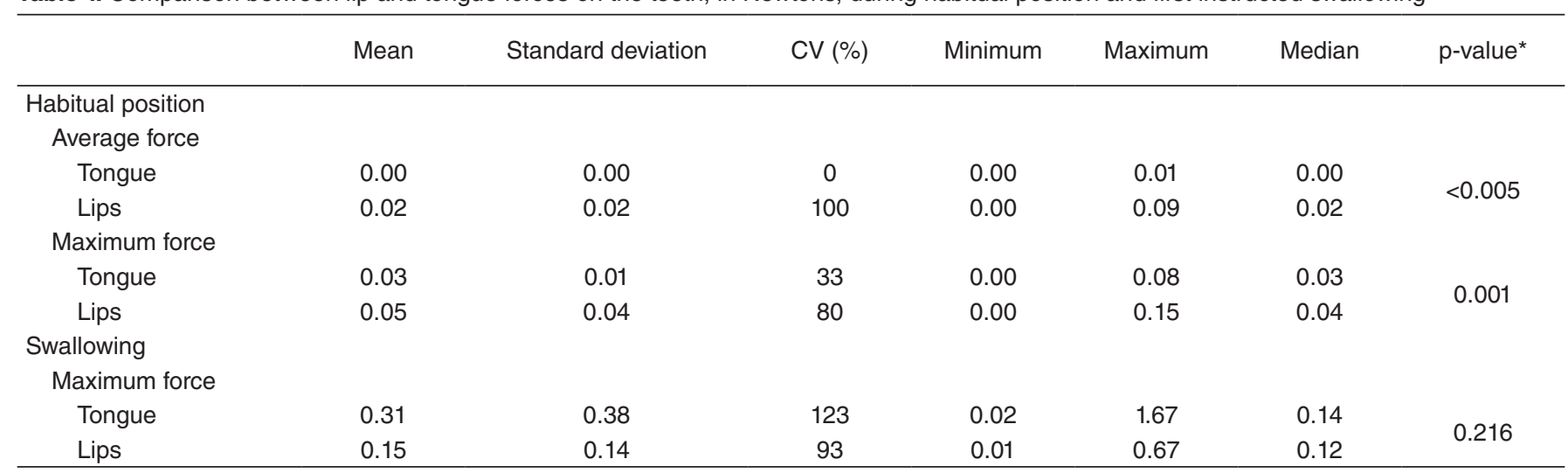

*Non-parametric Wilcoxon test

Caption: $\mathrm{CV}=$ coefficient of variation 
Table 2. Difference of forces suffered by the tooth with the action of tongue and lip, in Newtons, for each subject and total average, during habitual position and swallowing

\begin{tabular}{|c|c|c|c|}
\hline \multirow{2}{*}{ Subject } & \multirow{2}{*}{ Occlusion } & Habitual position & Swallowing \\
\hline & & Tongue-lip (N) & Tongue-lip (N) \\
\hline 1 & Normal & -0.04 & 0.36 \\
\hline 2 & Normal & -0.06 & 0.90 \\
\hline 3 & Normal & 0.00 & -0.09 \\
\hline 4 & Crossbite & -0.04 & -0.05 \\
\hline 5 & Normal & -0.09 & -0.19 \\
\hline 6 & Normal & 0.00 & 0.18 \\
\hline 7 & Normal & 0.00 & -0.60 \\
\hline 8 & Overjet, crossbite & -0.04 & 0.06 \\
\hline 9 & Overjet, overbite & -0.02 & -0.01 \\
\hline 10 & Overjet & 0.01 & -0.02 \\
\hline 11 & Normal & -0.03 & 0.00 \\
\hline 12 & Normal & -0.01 & 0.41 \\
\hline 13 & Normal & 0.00 & 0.30 \\
\hline 14 & Normal & -0.01 & -0.14 \\
\hline 15 & Normal & 0.00 & 0.93 \\
\hline 16 & Normal & -0.02 & 0.04 \\
\hline 17 & Overjet & -0.02 & 0.46 \\
\hline 18 & Normal & 0.00 & 0.02 \\
\hline 19 & Normal & 0.00 & -0.06 \\
\hline 20 & Normal & 0.00 & 0.10 \\
\hline 21 & Normal & 0.00 & -0.01 \\
\hline 22 & Normal & -0.02 & 0.32 \\
\hline 23 & Normal & 0.00 & 0.03 \\
\hline 24 & Normal & -0.02 & 1.35 \\
\hline 25 & Normal & -0.04 & -0.03 \\
\hline 26 & Open bite & -0.08 & 0.35 \\
\hline 27 & Normal & -0.02 & -0.10 \\
\hline 28 & Normal & -0.02 & 0.05 \\
\hline Mean & & -0.02 & 0.16 \\
\hline
\end{tabular}

\section{Time measurements}

The duration of the tongue's contact with the sensor during swallowing was analyzed on the subjects who had a visible tongue peak force. Table 3 shows the results.

\section{DISCUSSION}

Based on previous studies, the currently proposed method was developed so that the measurements would interfere as little as possible with orofacial functions. The choice of resistive sensors, which are equivalent to pressure sensors, was based on previous research which verified that the pressure transducer was the best instrument to measure lip force ${ }^{(15)}$.

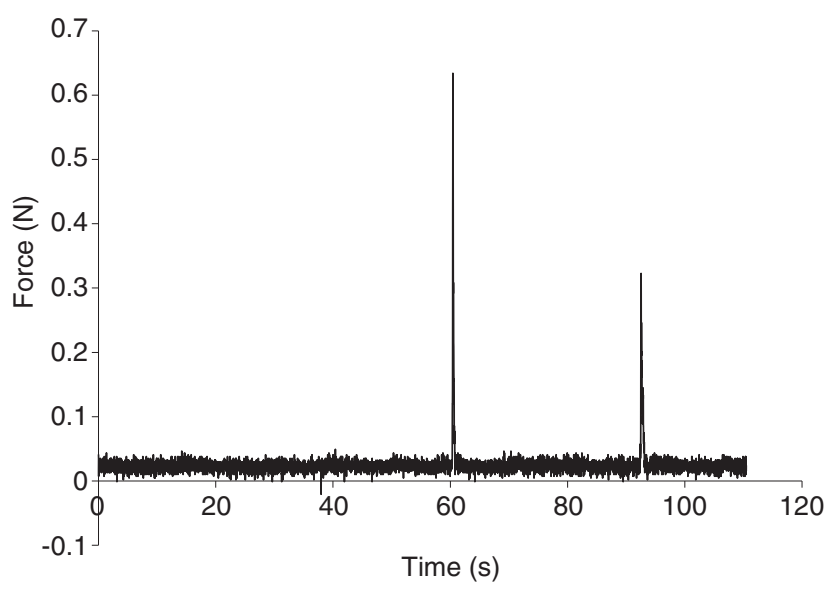

Figure 4. Tongue force versus time during the habitual position with two spontaneous swallows

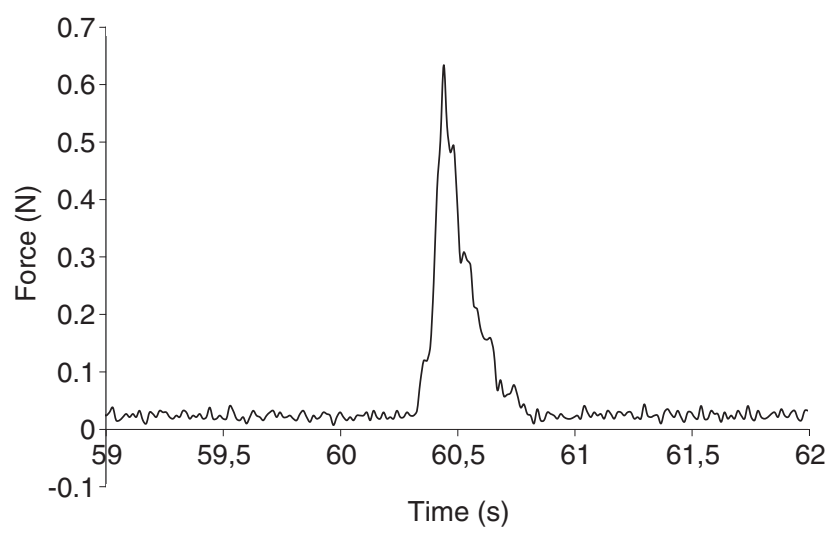

Figure 5. Tongue force versus time during swallowing, in detail

Another prerequisite for the sensors was that they were made of a flexible and biocompatible material ${ }^{(4)}$.

Tests verified that the proposed method was capable of measuring the forces experienced by the anterior tooth during the habitual position and during swallowing and that the method adapted well to different types of occlusion. As there is no gold standard instrument for this kind of measurement, it was not possible to validate the instrument. That is why the purpose of this paper is to present the method and provide results of a pilot study.

Most studies in the literature present results in pressure values. The force in this work is understood as the product of the pressure times the area. This implies that no large difference exists in the pressure distribution in the sensor area.

Table 3. Comparison of the time of tongue contact on the teeth, in seconds, between instructed and spontaneous swallowing

\begin{tabular}{lccccccc}
\hline & $\mathrm{n}$ & Mean & Standard deviation & Minimum & Maximum & Median & $\mathrm{p}$-value \\
\hline Instructed & 15 & 1.05 & 0.58 & 0.39 & 2.33 & 1.00 & 0.207 \\
Spontaneous & 15 & 0.80 & 0.47 & 0.22 & 2.04 & 0.80 & \\
\hline
\end{tabular}

*Non-parametric Wilcoxon test 
When other studies provide the pressure and sensor areas, the forces were calculated for the sake of comparison.

During the habitual position, the average and maximum lip forces were significantly higher than the average and maximum tongue forces $(\mathrm{p} \leq 0.001)$ (Table 1$)$. This indicates that the anterior teeth most times were pressed more on the labial surface. Many participants had an average tongue force of $0.00 \mathrm{~N}$ on the tooth. This was also the participants' average value, which could indicate that their habitual tongue position did not touch the upper incisor teeth.

The tongue force results in this study corroborate the findings of Ruan et al. ${ }^{(8)}$, who measured a force of $0.0005 \mathrm{~N}$, and Kennedy et al. ${ }^{(16)}$, who measured a force of $0.00 \mathrm{~N}$. Lip force values of $0.00 \mathrm{~N}$ were also found among the participants, but their average lip force was $0.02 \mathrm{~N}$. This was higher than values reported by Lapakti et al..$^{(3)}$, Ruan et al. ${ }^{(8)}$, Ruan et al ${ }^{(16)}$, and Ogushi et al. ${ }^{(10)}$, who verified lip forces of 0.0033 (at the incisal area of the teeth), $0.0022,0.00$, and $0.00003 \mathrm{~N}$, respectively; it was also smaller than the value of $0.17 \mathrm{~N}$ obtained by $\mathrm{Di}$ Fazio et al. ${ }^{(4)}$ The variation coefficient was quite high, possibly because of the forces magnitude, which was very small, in a region where the precision was lower.

About swallowing measures, saliva swallowing was chosen because it occurs 203-1,008 times each day in healthy adults $^{(17)}$. Therefore, as a frequently performed action, it can have a great impact on teeth.

There was no difference between forces exerted by the lip and the tongue during swallowing (Table 1). The tongue force on this task was lower than the force measured in a study $^{(12)}$ that measured a force of $0.72 \mathrm{~N}$ on the anterior palate, but the tongue force was higher than the force observed in studies by Frohlich et al. ${ }^{(11)}$, Ruan et al. ${ }^{(8)}$, Ruan et $\mathrm{al}^{(16)}$, and $\mathrm{Kieser}^{(9)}$, who reported forces of $0.0075,0.025$, 0.008 , and $0.0168 \mathrm{~N}$, respectively.

The values of the lip force on the same task (i.e., swallowing) were similar to the force reported in one study ${ }^{(4)}$ that used the same sensors as the current study and saliva swallowing $(0.172 \mathrm{~N})$. The values were higher than the forces reported by Lindeman and Moore ${ }^{(15)}$, Ruan et al. ${ }^{(8)}$, Ruan et al. ${ }^{(16)}$, and Kieser et al ${ }^{(9)}$, who reported forces of $0.00039,0.015,0.004$, and $0.00168 \mathrm{~N}$, respectively. However, all of the latter studies used water swallowing instead of saliva swallowing, thereby hampering comparisons.

The variation coefficients at swallowing were very $\operatorname{high}^{(9,18)}$. This may be because of variations in the amount of saliva swallowed each time. In this study, the standard deviations for the habitual position and swallowing were high, indicating considerable variation between individuals. One author ${ }^{(11)}$ also found a wide variation in these measures and explained that the variations are biological and unavoidable errors. A study ${ }^{(10)}$ furthermore reported a high standard deviation at the habitual position $(0.00003 \pm 0.00002 \mathrm{~N})$ and another study ${ }^{(16)}$ found high standard deviations during swallowing $(0.0018 \pm 0.0015$ and $0.00039 \pm 0.00026 \mathrm{~N})$. Both studies evaluated only subjects with normal occlusion. This suggests that measurements of these tasks actually exhibit great variations between subjects.
To verify the balance between the lip and tongue forces, the lip force was subtracted from the tongue force (Table 2). Most subjects had no force balance (i.e., the result of the subtraction was not zero) at the habitual position. This corroborates the findings of a study that evaluated tongue and cheek forces on the posterior teeth and verified unbalance ${ }^{(19)}$. Most subjects had a lip force that was higher than the tongue force. All ten subjects who had balance at the habitual position also had normal occlusion.

Only one study participant presented balance between the tongue and lip force during swallowing, and this participant had normal occlusion (Table 2). Among the remaining participants, 16 had a greater tongue force (which agrees with the findings of some authors ${ }^{(19)}$ ), whereas 11 participants had a greater lip force. It may be that the high frequency of a greater lip force may result from the fact that the sensor makes lip sealing more difficult. Thus, some subjects may have pressed the sensor as a consequence of a forced lip seal, and this may have introduced a bias in the study.

The analysis of the forces verified that the lack of balance between the tongue and lip forces on the tooth does not indicate malocclusion since many subjects with normal occlusion had no balance at the habitual position, or during deglutition, or even on analyzing the final results of both tasks. Therefore, to affect tooth positioning, it may be necessary to have a larger unbalance of approximately $0.1 \mathrm{~N}$, which is the minimum orthodontic force according to Proffit et al. ${ }^{(1)}$. One study ${ }^{(20)}$ reported that a force of $0.01 \mathrm{~N}$ is capable of causing tooth movement, but the displacement was verified only at the moment of the evaluation; thus, it is unknown whether such small forces can cause permanent tooth movement. A possible explanation for the finding that subjects with normal occlusion had a tongue and lip resultant force that was not $0.00 \mathrm{~N}$ is that the large intermittent swallowing forces balance the small constant habitual position forces. This way, there is no force equilibrium at a certain moment, but it occurs over a long time.

Speech-language pathologists usually evaluate swallowing by asking the patient to swallow. So, it is important to know if this instructed swallowing is similar to the spontaneous swallowing, that the patient does many times a day, to certify that what is assessed is the real condition of the subject. That is why those two types of swallowing were compared. The comparison of the forces showed that lip forces were slightly greater with spontaneous swallowing than instructed swallowing; this contrasts with the finding of another study ${ }^{(7)}$. The greatest tongue forces were also found in the same task. A possible explanation for this finding is that with instructed swallowing the participants may have monitored the force of the orofacial structures. In other words, the participants focused on controlling the forces when they were told to swallow, but they did not do this when they swallowed naturally.

The duration of the tongue touch on the sensor during both types of swallowing was also compared and analyzed (Table 3 ). No difference existed between the duration of spontaneous and instructed swallowing, which was expected because the swallowed content (i.e., saliva) was the same. The time of instructed swallowing in this study was 1.05 seconds. This agrees with the 
time ( 0.90 seconds) reported in one study ${ }^{(12)}$, but it was slightly longer than the time ( 0.72 seconds) found in another study that used young people ${ }^{(14)}$. Both studies used sensors attached to the palate and evaluated water swallowing.

The sample of the current study was very heterogeneous with subjects with and without malocclusion and/or without muscular dysfunctions because the main purpose of this study was to present the method. Therefore, the results may have been affected by these variables. It was not possible to analyze forces on each type of malocclusion because there were only a few individuals for each category. Future studies should recruit a larger number of individuals with each malocclusion type in order to investigate the differences each anatomical variation has on tongue forces.

The proposed system quantifies the forces of the orofacial muscles. This can assist speech-language pathologists in making a more accurate diagnosis and can be used in scientific research. The authors suggest that future work use wireless sensors so that there is no interference on lip sealing. If possible, sensors should have a smaller measurement range so that forces close to $0.00 \mathrm{~N}$ can be perceived more accurately. The sensors should also be positioned on the alveolar region of the upper and lower teeth, which will enable mapping where the forces are exerted. It is also important that future studies have larger sample sizes, including more subjects with malocclusion (chiefly anterior open bite and increased overjet), and evaluate a greater number of instructed and spontaneous swallows. The authors also suggest that longitudinal studies should be performed before and after orthodontic treatment and/or before and after speech-pathology therapy.

\section{CONCLUSION}

The method in the current study was capable of measuring forces of the tongue and lip on the tooth, and is characterized as an important tool in the speech-language pathology and odontology fields. During the habitual position, lip forces were greater than tongue forces; however, no difference existed during swallowing. Most subjects presented no balance between the tongue and lip forces on the tooth during the habitual position, during swallowing, or even when considering the results of both. The duration of the tongue touch on the tooth was similar with instructed and spontaneous swallowing.

*AFV conducted literature review, study design, data collection, analysis and discussion of data and wrote the text; RMMMF conducted the study design, analysis and discussion of data and wrote the text; TVCP and MCBB performed the study design, analysis and discussion of data; ARM and EBLC conducted the study design, orientation and correction of the text.

\section{REFERENCES}

1. Proffit WR, Fields HW Jr, Sarver DM. A etiologia dos problemas ortodônticos. In: Proffit WR, Fields HW Jr, Sarver DM. Ortodontia contemporânea. $4^{\mathrm{a}}$ ed. Rio de Janeiro: Elsevier; 2007. p. 121-53.

2. Clark HM, Henson PA, Barber WD, Stierwalt JAG, Sherrill M. Relationships among subjective and objective measures of tongue strength and oral phase swallowing impairments. Am J Speech Lang Pathol. 2003;12(1):40-50

3. Lapakti BG, Mager AS, Schulte-Moenting J, Jonas IE. The importance of the level of the lip line and resting lip pressure on Class II Division 2 malocclusion. J Dent Res. 2002;81(5):323-8.

4. Di Fazio D, Lombardo L, Gracco A, D'Amico P, Siciliani G. Lip pressure at rest and during function in 2 groups of patients with different occlusions. Am J Orthod Dentofacial Orthop. 2011;139(1):e1-e6.

5. Takahashi S, Ono T, Ishiwata Y, Kuroda T. Effect of changes in the breathing mode and body position on tongue pressure with respiratory-related oscillations. Am J Orthod Dentofacial Orthop. 1999;115(3):239-46.

6. Taslan S, Biren S, Ceylanoglu C. Tongue pressure changes before, during and after crib appliance therapy. Angle Orthod. 2010;80(3):533-9.

7. Kydd WL, Akamine JS, Mendel RA, Kraus BS. Tongue and lip forces exerted during deglutition in subjects with and without an anterior open bite. J Den Res. 1963;42(3):1-9.

8. Ruan W, Chen M, Gu Z, Lu Y, Su J, Guo Q. Muscular forces exerted on the normal deciduous dentition. Angle Orthod. 2005;75(5):785-90.

9. Kieser J, Singh B, Swain M, Ichim I, Waddell JN, Kennedy D, et al Measuring intraoral pressure: adaptation of a dental appliance allows measurement during function. Dysphagia. 2008;23(3):237-43.

10. Ogushi S, Hisanaga Y, Hasegawa A, Kawanabe H, Ishikawa H. Lip and cheek resting pressure on the maxillary dentition in adults with normal occlusion. Orthodontic Waves. 2008;67:54-9.

11. Frohlich K, Thuer U, Ingervall B. Pressure from the tongue on the teeth in young adults. Angle Orthod. 1990;61(1):17-24.

12. Ono T, Hori K, Nokubi T. Pattern of tongue pressure on hard palate during swallowing. Dysphagia. 2004;19(4):259-64.

13. Hori K, Ono T, Iwata H, Nokubi T, Kumakura I. Tongue pressure against hard palate during swallowing in post-stroke patients. Gerodontology. 2005;22(4):227-33

14. Tamine K, Ono T, Hori K, Kondoh J, Hamanaka S, Maeda Y. Agerelated changes in tongue pressure during swallowing. J Dental Res. 2010;89(10):1097-101.

15. Lindeman DE, Moore RN. Measurement of intraoral muscle forces during functional exercises. Am J Orthod Dentofacial Orthop. 1990;97(4):289-300.

16. Ruan WH, Su JM, Ye XW. Pressure from the lips and the tongue in children with class III malocclusion. J Zhejiang Univ Sci B. 2007;8(5):296-301.

17. Lear CSC, Flanagan JB, Moorrees CFA. The frequency of deglutition in man. Arch Oral Biol. 1965;10(1):83-99.

18. Kennedy D, Kieser J, Bolter C, Swain M, Singh B, Waddell JN. Tongue pressure patterns during water swallowing. Dysphagia. 2010;25(1):11-9.

19. Lear CSC, Moorrees CFA. Bucco-lingual muscle force and dental arch form. Am J Orthod. 1969;56(4):379-93.

20. Lear CS, Decou RE, Ng DH. Threshold levels for displacement of human maxillary central incisors in response to lingually directed forces. J Dent Res. 1974;53(4):942. 